\title{
Editorial: Time to take stock
}

\section{John Bynner}

The most recent editorial committee meeting on 20 April signaled major changes in its membership see inside the cover of this issue for a full list of members. This is therefore a good time to take stock of the journal's progress.

\section{Progress overview}

Good to remember that the origins of the journal lie in a 2007 initiative of the think tank Longview. At a time when national investment in longitudinal data was developing fast, accompanied by an expanding program of research based on it, longitudinal data was seen as under-used, especially by policy makers. There was also a gap in the scientific literature that needed filling. A new scientific journal was seen by Longview as the answer and with the help of a Nuffield Foundation three-year development grant, Longitudinal and Life course Studies was launched with a first issue in April 2009.

What was it that needed promoting? As the first Editorial put it "Longitudinal research is founded on a set of principles and procedures directed at yielding insights into possible causal connections among social, biological and developmental phenomena. Life course study reflects the loosening of disciplinary boundaries in the fields particularly of psychology, sociology, economics, health and history to reflect the growing recognition that the developmental pathways and transitions through which the human life course is constructed are shaped by multiple influences. These include the changing institutions, social structures, and historical era in which development begins."

Longitudinal research is thus the vehicle par excellence for mapping the changing human life course within a generation and across generations as development and ageing proceeds through repeated longitudinal studies. Starting in different historical periods, life course study offers a means of showing how the life course is shaped and reshaped through the interactions between changing societal circumstances and individual and collective agency.

\section{Appraisal}

Has the ambition of the early days been realised?
The signs are that it has but as the data, analytic and policy contexts change at an ever-increasing rate there will always be ground to be made up. From the starting point of three issues a year, we switched in 2015 to four. The current issue is the second in the eighth volume of the journal's output, comprising 159 peer-reviewed papers in 25 individual issues. More than 2,000 registered readers of the journal are now located in 25 different countries across the world and that number is continually expanding. Our output and submissions continue to rise as more and more authors come to see the journal as the vehicle of choice for their longitudinal and life course study publications. Recognition of the journal's achievements is reinforced by its location in such citation databases as Scopus and Thomson Reuters' Emerging Sources.

These progress indicators have paralleled the phenomenal expansion of investment in longitudinal data and in life course study as the means of exploiting it. Despite the setbacks associated with termination of two of the most ambitious programs, such as the US National Children's Study and the UK Life Study, both beginning in pregnancy, the general trend has been upwards with a combination of technological, theoretical and analytic advances making access and use of data - including now 'Big Data' - ever easier. From data enrichment from administrative sources to biomarkers extending to DNA, ever-improving measurement methods, new statistical methods and increasingly flexible software for using and improving them, are transforming the longitudinal research experience and the institutionalisation of life course study as a major science is now assured ${ }^{2}$.

Such developments extend in important ways to the next generation through the common strategy of following cohort members' children. As major studies, such as household panels, ageing studies and increasingly birth cohorts harmonise their methods across countries, the life course becomes researchable comparatively. Such intra-cohort and inter-cohort comparison within multilevel statistical frameworks are perhaps the most significant 
developments of all in the new era.

The conclusion must be that by a good luck and judgment the journal was developed at the right time and will continue to thrive.

\section{This issue}

The papers in this Issue reflect the conclusions of the previous section through the richness of the journal's coverage.

We start with a study using the US Health and Retirement study data to model the effects of combat exposure during military service as it affects health in later life. The next paper similarly examines health effects, this time arising from the disturbance of sleep patterns as a mediator of chronic medical conditions on depressive symptoms over time. We then move to a comparative study, using Household Panel study data, of the relationship between civic engagement and the education systems operating in England and Germany. A study of wage differentials following a career break using Belgian register data comes next. The final research paper reviews longitudinal methods, in this case comparing the popular sequence analysis with latent class growth models and multistate event history models, as exemplified by Norwegian partnership transition research. A different mode of publication follows in the form of the final paper - a Study Profile devoted to the widely regarded Swiss two-cohort TREE (transition from education to employment) study.

\section{Editorial Committee}

The story would not be complete without the most significant development with which this editorial began. As the periods of office of current members of the editorial committee come to an end we have new faces in key positions now ratified by the April meeting of the committee.

As one of the last of the original group of five Michael Wadsworth, Robert Eriksson, Barbara Maughan and Harvey Goldstein - who established the journal I have now handed over the role of Executive Editor to Heather Joshi (UCL Institute of Education). As Emeritus Professor of economic and developmental demography, previous director of the UCL Centre for Longitudinal Studies and first elected president of the Society for Longitudinal and Life course studies, Heather is perfectly placed to give the editorial leadership the journal needs.

The other founder member, Harvey Goldstein -coeditor of Statistical Society Series A (Statisticas in Society) and a key contributor to the journal's policy development - has for the last three years been sharing with Kate Tilling (Bristol) the Section Editor role for Statistical Sciences and Methodology. He has now completed the full handover to Kate.

Following Richard Layte (Trinity College) having to stand down we now have a new Section Editor for Social and Economic Sciences, Peter Elias, Institute for Employment research University of Warwick. With a background in Applied Labour Economics in Berkeley, past Strategic Adviser for Data Resources to the UK Economics and Social Research Council (ESRC) and a research career drawing extensively on longitudinal data, Peter brings a wealth of invaluable experience to the journal.

New Associate Editors (AEs) appointed last September will also begin their terms of office from 20 April. Health Sciences - Cyrille Delpierre, (Inserm). Michelle Kelly-Irving (Inserm); Statistics and Methodology - Gita Mishra (Queensland), Tim Croudace (Dundee); Behavioural Sciences and Development - Dale Dannefer (Case Western Reserve), Jutta Heckhausen (UC Irvine); Economic and Social Sciences - Bram Vanhoutte (Manchester).

Our gratitude for their great contributions to the journal goes to Richard Layte David Blane, Amanda Sacker, Jan Smit, Lars Bergman, John Hobcraft and Paul Gregg.

\section{Conclusion}

In short the journal is on target for achieving its early aims and the new editors will add further to its strengths. It is only left for you, the readers, to promote whenever you get the chance the journal's value as a key scientific resource and the ideal platform for longitudinal and life course research reporting. We value highly your engagement with the journal and welcome your ideas for developing it further. 